\title{
Peyzaj Mimarlığında Alternatif Bir Öğrenme Aracı: Film Peyzajları ve Potansiyel Katkıları
}

\author{
An Alternative Learning Tool in Landscape Architecture: \\ Filmic Landscapes and Their Potential Contributions
}

\author{
Sema MUMCU
}

Öz

Film yeni bir teknoloji değildir ve peyzaj mimarlığı bağlamında potansiyel bir eğitim ve araştırma aracı olabilir. Peyzaja ilişkin araştırmalarda kelimeler bilmenin geçerli yolu olmakta ve görsel olan “öteki” olarak kalmaktadır. Oysa film peyzajlarının da içinde yer aldığı görsel araştırmalar aracılığıyla kelimeler ile görüntüler ve peyzaj mimarlığı uygulamaları ile teorileri arasında verimli ilişkiler kurulabilir. Film peyzajlarının peyzaj mimarlığı eğitim ve araştırmalarında yeterince yaygın olmadığı kabulünden yola çıkarak bu çalışmada potansiyel kullanımları ve katkıları tartışılmıştır. Film peyzajlarını ele alan film, beşeri coğrafya, sosyoloji ve mimarlık araştırmaları detaylıca taranmış, film peyzajları aracılığıyla irdelenen konular saptanmış ve bunların peyzaj mimarlığıyla ilişkileri tartışılmıştır. Film peyzajları aracılığıyla temelde iki alana yönelik tartışmalar yürütülmüştür; insan-insan/insan-çevre ilişkisinin anlaşılması ve peyzaj mimarlığı/mimarlık eğitiminde kullanımları. Film peyzajları aracılığıyla modernizmin etkileri, cinsiyet rolleri, savaş-yıkım, sömürgecilik tarihi, insanın psikolojik süreçleri, çevresel sorunlar ve farkındalık gibi çok çeşitli konuların ele alınabildiği görülmüştür. Bunlar yanında film peyzajlarının mekânsal tasarıma algısal, kavramsal ve sosyal katkılarının neler olabileceği, bunların peyzaj mimarlığı eğitiminde nasıl kullanılabileceği de tartışılmıştır. Sonuç olarak film peyzajlarının hiçbir zaman insan eylemleri ve anlamlarından bağımsız salt fiziki bir ortam olarak ele alınmadığı, tersine karmaşık ilişkiler sergileyen, açık uçlu ve çok katmanlı bir yapı olarak ortaya koyulduğu görülmüştür. Bu, peyzaj mimarları için tasarım sürecinde peyzajın içerdiği ilişkiler ve süreçlerin karmaşıklığının daha iyi anlaşılması ve çevresel farkındalığın artırılması anlamlarına gelir. Ayrıca eğitim boyutunda film peyzajlarının üç boyutlu düşünme, senaryo geliştirme ve mekân-zaman, mekân-hareket ilişkisinin anlaşılması gibi konularda yardımcı olabileceği de ortaya koyulmuştur.

Anahtar sözcükler: Çevresel farkındalık; cinsiyet rolleri; film peyzajları; insan-çevre ilişkisi; mekânsal tasarım; peyzaj mimarlığı.

\section{ABSTRACT}

Film is no new technology and can be a potential teaching and research tool in landscape architecture context. In landscape architecture researches words are pertinent way for knowing and the visual remains Other. However, fruitful relationships between words and images and between practices and theories of landscape architecture can be develeoped through critical visual studies in which filmic landscapes are included. Based on the assumption that film landscapes are not sufficiently widespread in landscape architecture education and research, their potential uses and contributions are discussed in this study. Film, human geography, sociology and architectural researches that considered filmic landscapes were scanned in detail, the subjects discussed through film landscapes were determined and their relations with landscape architecture were discussed. Through the landscapes of the films, there were basically two debates; understanding of human-human / human-environment relationship and their use in landscape architecture/architectural education. Through filmic landscapes, it has been seen that various issues such as the effects of modernism, gender roles, war-destruction, history of colonialism, psychological processes of human beings, environmental problems and awareness can be addressed. In addition to these, the perceptual, conceptual and social contributions of filmic landscapes to spatial design, and how these can be used in landscape architecture education are also discussed. As a result, it has been revealed that filmic landscapes have never been considered as a purely physical environment independent of human actions and meanings, but rather as an open-ended and multi-layered structure with complex relationships. For landscape architects this means a better understanding of the complexity of the relationships and processes involved in the landscape in the design process and increasing their environmental awareness. In addition, it has been revealed that filmic landscapes can help in three dimensional thinking, scenario development and understanding space-time, space-movement relationship in educational context.

Keywords: Environmental awareness; gender roles; film landscape; human-environment relationship; spatial design; landscape architecture.

Karadeniz Teknik Üniversitesi Orman Fakültesi, Peyzaj Mimarlığı Bölümü, Trabzon 


\section{Giriş}

Film yeni bir teknoloji değildir. Arttk gündelik hayatın pek çok alanında (hareketli görüntülerin yer verildiği reklam panoları, mobil telefonlardaki uygulamalar vb. gibi) karşımıza çıkan filmler peyzaj mimarlı̆̆ında potansiyel bir eğitim/öğretim aracı olabilirler. Dee ${ }^{1}$ film çalışmalarının da içinde yer aldığı görsel araştırmaların, peyzaj mimarlığında teori ve uygulama kopukluğunu birleştirmek için kullanılabileceğini belirtmiştir. Peyzaj mimarları ve tasarım öğrencileri görüntüleri öncelikle tasarımları anlatmak ve geliştirmek amacıyla kullanırken, peyzajın sosyal, felsefi ve kültürel yönlerini araştırmak ve incelemek için daha az sıklıkta kullanmaktadırlar. Peyzaja ilişkin araştırmalar bağlamında kelimeler bilmenin geçerli yolu olmakta ve görsel olan "öteki" olarak kalmaktadır. Oysa "eleştirel görsel araştormalar" olarak adlandırılan araştırmalar, yazılı akademik araştırmalara katkıda bulunabilirler. Görsel araştırmaların kelimeler ile görüntüler ve peyzaj mimarlığı uygulamaları ile teorileri arasında verimli ilişkiler kurma potansiyeli vardır. Görsel araştırma türleri içinde filmler, görüntüler ve kelimelerin güçlü bir etkileşimini sağlamada en çok potansiyele sahip olan türdür. ${ }^{2}$

2000'li yıllardan itibaren peyzaj ve film ilişkisi giderek artan bir şekilde farklı disiplinlerce dile getirilmekte, farklı açılardan faydaları ortaya koyulmaktadır. Fridh ${ }^{3}$ filmi günümüz toplumunun parçalanmış ve hareketli dünya görüşünü yansıtmak ve tartş̧mak için iyi bir araç olarak tanımlar. Yazara göre, çevre ile ilişki kurulmasında kameranın yardımıyla öznel yaklaşımların açıklığa kavuşturulması, doğrudan fiziksel çevre ile çalışan peyzaj mimarları gibi disiplinler için büyük bir potansiyel taşır. ${ }^{4}$ Lefebvre, ${ }^{5}$ peyzajın diyalektik yönleri üzerinden yakınlık ve mesafe, beden ve akıl, duygusal olarak içinde olma (imersiyon) ve uzaktan gözlemleme arasında bir gerilim olduğunu belirtir. Peyzaja ilişkin bu gerilim kendini en canlı haliyle sinemada ortaya koyar ve bir dereceye kadar çözümlenir. Konunun temelinde sinemanın benzersiz olan mekân ve zaman, görüntü ve hikâyeyi, peyzaj gösterimleri içinde ortaya çıkarma yeteneği vardır. ${ }^{6}$ Weihsmann, ${ }^{7}$ filmi sanatçılar, film yapımcıları ve mimarlar için yeni ve deneysel bir araç olarak tanımlar. Gandy'e ${ }^{8}$ göre sinema peyzajları yer, mekân ve doğaya ilişkin kültürel temsillerin incelenmesi için zengin firsatlar sağlarlar. Sinema peyzajları ile mimarlık teorisi, coğrafya, sosyoloji ve diğer disiplinler arasında eleştirel araştırma türleri bakımdan bağ olduğu belirtilir. Belirtilen bu çalışmalar, film ve peyzaj arasındaki bağın araştırılmasına ya da bu bağın peyzaj mimarları için gelişimsel/eğitsel araç olarak önemini yansıtmaktadırlar. Bu çalışma, peyzaj ve film arasındaki bu bağın daha derinlemesine anlaşılmasını ve

Fridh, 2006:70.
}

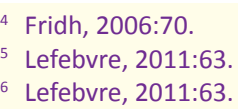

8 Gandy, 2003:218. peyzaj mimarlığında hem eğitim hem de araştırma aracı olarak kullanılma yollarını tartşmayı amaçlamaktadır. Bu bağlamda bu çalışmada başlıca iki alandan çalışmalar incelenmiştir:

(1) Sinema, belgesel, televizyon dizisi, animasyon/anime gibi çeşitli filmlere dair araştırmalar incelenmiş; bunlardan ele aldıkları konuları (savaş, cinsiyet rolleri, modernizm vb. gibi), ele aldıkları film(ler)in içerdiği peyzajla açık bir ilişki kurarak tartışanlar seçilmiştir. Seçilen bu çalışmalardan hiçbiri peyzajla ilişki kurarken ya da peyzaja gönderme yaparken peyzaj mimarlığı mesleği ya da eğitimine değinmemiştir. Eksik kalan bu boyuta bu çalışma aracılığıyla değinilmesi amaçlanmıştır.

Bir filme ya da bir konudaki filmlere odaklanan bu kültürel araştırmaların dışında çalışma kapsamında; (2) film peyzajlarını eğitsel araç olarak kullanmayı öneren araştırmalar da incelenmiştir. Bu araştırmaların önerileri doğrultusunda peyzaj mimarlığı eğitiminde bunların nasıl çeşitlendirileceği tartş̧ılmıştır.

\section{Film Peyzajları}

Filmlerde yer alan peyzajların anlaşılabilmesi için öncelikle peyzaj kavramı ele alınmalıdır. Peyzaj, doğa ve uygarlık, yeryüzü ve insan arasındaki karşılıklı ilişkiler olarak ele alınır. ${ }^{9}$ Insan-çevre ilişkisinin araştırımasında doğa, çevre ve peyzaj kavramları iç içe geçmişlerdir. Lefebvre'ye ${ }^{10}$ göre peyzaj ve doğa arasındaki en önemli ayırt edici farklılık, toplumsal belleğin peyzajın içine yerleşmiş olmasıdır. Bu, peyzajı insan ürünü yapar. Greider ve Garkovich ${ }^{11}$ peyzajı insanların doğa ve çevre üzerine anlamlar yüklemesi ile oluşturulan sembolik çevreler olarak tanımlar. Kültürel bağlam doğrultusunda doğa ve çevreyi tanımlayan simgeler ve anlamlar inşa edilirler ve bu tanımlar aracılığıyla fiziksel çevreler peyzaja dönüştürülür. ${ }^{12}$ Peyzaja ilişkin pek çok başka tanım bu sosyal inşa boyutunu paylaşırken bu kavramın farklı boyutlarını vurgulayarak açılımını genişletir. Avrupa Peyzaj Sözleşmesi peyzajı "insanlar tarafindan algılandığı şekliyle karakteri doğal ve/veya kültürel (yani insani) unsurların eyleminin ve etkileşiminin sonucu olan bir alan olarak" tanımlar. "Bu tanım, doğal güçler ve insanların üzerinde uyguladığı eylemler sonucunda peyzajın zaman içinde değiştiğini yansıttr." ${ }^{13}$ Bu tanıma paralel olarak Bigell ve Chang ${ }^{14}$ peyzajı durağan bir görüntü değil de çevreyi biçimlendiren tarihi ve doğal güçlerin ifadesi/anlatımı olarak tanımlar. Saunders ${ }^{15}$ peyzajın gerçek fiziksel niteliklere sahip olduğunu ancak inşasının sosyal, kültürel, ekonomik ve politik süreçler aracılığıyla gerçekleştiğini belirtir. Bu tanımlar doğal ve kültürel güçlerin peyzajdaki değişimlerin

\footnotetext{
9 Cardwell, 2006:26.

${ }^{10}$ Lefebvre, 2011:70.

${ }^{11}$ Greider ve Garkovich, 1994

12 Bigell ve Chang, 2014.
}

\footnotetext{
${ }^{13}$ Avrupa Birliği, 2004.

${ }^{14}$ Bigell ve Chang, 2014.

${ }^{15}$ Saunders, 2013.
} 
iki bileşeni olarak tanımlanabileceğini gösterir. Toplumların çevreleriyle ilişkilerini nasıl tanımladıkları, kültürel güçlerin önemli bir yönüdür. Peyzajları oluşturan kültürel tanımlamalar, potansiyel insan etkilerini tanımlama ve anlamanın anahtarıdır. ${ }^{16}$

Film peyzajları yalnızca kültürel tarih ile ilişki değildir, peyzajın kendisinde olduğu gibi ayrıca politik amaçlar ve daha geniş bir bağlam içerirler. Beraberinde sorular getirir, soruların cevabı olarak gelirler. Ekolojik konuları buluştururlar. Peyzajlar, ırk kavramı ve cinsiyet rollerine ilişkin mecazlar taşırlar. İnsanların doğayla, birbirleriyle, yerle ve zamanla etkileşimlerini incelerler. ${ }^{17}$ Tüm bu bağlantıları nedeniyle film, peyzajın yorumlanmasına ilişkin bir anlayışa ulaşmakta ideal bir araç olarak tanımlanmıştr. ${ }^{18}$ Bir parça/ metin/hikâye olarak filmler, yerlere ilişkin görüşümüzü ve görmemizi biçimlendirirler. Bu tür yerler izleyicilerin zihinlerinde hayali haritalar oluştururlar. ${ }^{19}$ Peyzajla çeşitli şekillerde girilen her etkileşim, her kişiyi ve hayal güçlerini bir andan bir ana ve bir durumdan diğerine farklı farklı etkileyecektir. ${ }^{20}$

Görsel açıdan cezbedici görünümler ve manzaralar, her zaman için sinema deneyiminin en önemli parçası olmuşlardır. ${ }^{21}$ Ancak görüntünün/imgenin ötesinde peyzajın kurgu filmlerde üstlenebildiği 4 işlev vardır: yer, mekân, manzara ve metafor. ${ }^{22}$ Peyzaj, filmdeki en özgür ögedir; ruhsal atmosferin, duygusal durumların ve ruhsal deneyimlerin iletilmesinde en esnek elemandır. ${ }^{23}$ Peyzaj, filmlerde zaman-mekân duygusu oluşturur. Hikâyeyi daha çeşitli ritimlerle donatmak işlevini üstlenir, filmlerin görselliğini güçlendirebilir, izleyicinin mekânsal kavrayışına müdahale edebilir ve yönlendirebilir. Ayrıca karakterlerin karmaşık psikolojilerinin görsel analojileri olarak rol üstlenir, sinematik olaylara anlam kazandırır ve öyküyü belirli bir ölçeğe ve tarihi bir bağlama yerleştirir. ${ }^{24,25}$ Bu nedenlerle, peyzajın filmlerde üstlendiği rol sinematik mekânın oluşumunda merkezi bir yere sahiptir. ${ }^{26}$ Film deneyimi ve sinematik mekân/peyzaj arasındaki ilişkiyi ele alırken Bruno, ${ }^{27}$ filmin izlemek, değerlendirmek ve gezinmek için mekânlar oluşturduğunu öne sürer. Film peyzajları aracılığıyla seyahat ederken, mekânlar ve olaylar arasında öyküyü oluşturan ve dönüştüren ilişkiler gelişir. ${ }^{28}$ Filmlerin hareketli görüntüleri hem peyzajın yorumlanmasına hem de insanın kendisini ve görüş alanını anlamasına yeni boyutlar katar. Sabit bir perspektiften kurtulmak izleyiciyi de özgürlüğüne kavuşturur, böylelikle olası ilişkiler ve eylemlere dair daha büyük bir farkındalık ortaya çıkar. Aracı olunan bu mekânsal deneyim iki boyutlu planlara yüklenenlerden tamamen farklıdır. ${ }^{29}$

\footnotetext{
${ }^{16}$ Greider ve Garkovich, 1994. ${ }^{21}$ Lefebvre, 2011:65.

17 Harper G ve Rayner J (2013).

${ }^{22}$ Lukinbeal, 2005:5.

${ }^{26}$ Lukinbeal, 2005:3

18 Stieve, 2013:168.

${ }^{19}$ Moran, 2006:225.

${ }^{20}$ Curti, 2008.

24 Dissanayake, 2010.

${ }^{29}$ Fridh, 2006:16.
}

Peyzaj genellikle filmlerde gerekli olan arka planın sağlayıcısı olarak kabul edilmiştir. Ancak peyzaj yukarda da belirtildiği gibi, film deneyimine daha büyük anlam ve önem katan çok daha ustaca, çok sayıda başka işlevleri filmlerde gerçekleştirir. ${ }^{30}$ Bu nedenle film peyzajlarının durağan arka planlar olarak değil de rol yapan/sahne alan peyzaj anlayışıyla; yaşamın bir ifadesi, başlı başına bir oyuncu ya da çalışan, altta yatan temaların görsel işleyicisi, kendi aktif gücüne, mücadelesine, yetkisine sahip bir yönetmen olarak anlaşılmaları gerektiği belirtilir. ${ }^{31-35}$ Insani ve geçici ögeleri ve topoğrafyasıyla peyzajın tümü öznedir, konunun kendisidir. ${ }^{36,37}$

\section{Film Peyzajlarının Peyzaj Mimarlığında Nasıl Kullanılabileceğinin Değerlendirilmesi}

Film peyzajlarının peyzaj mimarlığı eğitim ve araştırmalarındaki potansiyel kullanımları; 1) insan-insan/insan-çevre ilişkisinin anlaşıması ve 2) peyzaj mimarlığı/mimarlık eğitiminde bir araç olarak kullanılması başlıkları altında çeşitli filmlerden ve araştırmalardan örnekler aracılığıyla irdelenip çeşitlendirilmişlerdir. Filmler; belirli bir konuyu, peyzajla ilişkili bir şekilde tartş̧an araştırmalardan seçilmişlerdir. Bu araştırmaların film peyzajına dair bulgularının, peyzaj mimarlığı bakımından potansiyellerinin neler olabileceği tartışılmıştır. Ancak film peyzajlarının peyzaj mimarlığında kullanım potansiyeli burada sunulanlardan çok daha fazladır ve zamanla bunların daha da gelişeceği ön görülmektedir. Ayrıca burada ele alınan başıkları birbirlerinden kesin bir şekilde ayırmak mümkün değildir, zira insan-çevre ilişkisinin anlaşılması peyzaj mimarlığı eğitiminin de temelini oluşturmaktır. Illk kısımda film peyzajlarının anlamsal, toplumsalsosyal ve psikolojik yönlerinin anlaşılması üzerinde durulacaktır. İkinci kııımda ise mekân tasarımının anlaşılmasına algısal, sosyal ve anlamsal katkıları bağlamında eğitim sürecinde nasıl kullanılabilecekleri tartışılacaktır.

\section{Filmlerdeki Peyzajlar Aracılığıyla İnsan-İnsan/ İnsan-Çevre İlişkisinin Anlaşılması}

Film çalışmalarında, filmlerdeki peyzajlar aracılığıyla pek çok konunun tartşılabildiği görülmüştür. Bunlar; modernliğin deneyimlenmesi ve yabancılaşma, teknolojik belirsizlik, modern peyzajların ölçü ve dinamizmi; ${ }^{38}$ çiftçilik, tarım peyzajları, ekonomik ve politik hareketlilik ${ }^{39}$ aile, arkadaşıık, yalnızlık, göçmen hikâyeleri, ulusal peyzajlar, çağdaş yaşam tarzı ${ }^{40}$ doğal peyzaj, yabanıl alan sınırları (çöl, nehir, el değmemiş tropik ormanlar), kendini keşfetme, hayal kırıklığı, sömürgecilik ve Avrupa ve Amerika'nın sömürgeci politik tarihi, Üçüncü Dünya kültürleri; ${ }^{41}$ teknoloji ve doğa

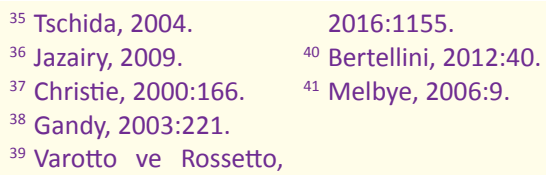

2016:1155

${ }^{40}$ Bertellini, 2012:40.

${ }^{41}$ Melbye, 2006:9.

\footnotetext{
${ }^{30}$ Dissanayake, 2010.

${ }^{31}$ Curti, 2008.

${ }^{32}$ Lukinbeal, 2005.

${ }^{33}$ Melbye, 2017:108.

${ }^{34}$ Pandian, 2011:55.
} 
ilişkisi, savaş-savaş sonrası travma, terörizm-biyogüvenlik, 9/11, derin ekoloji ve iklim değişikliği, umutsuzluk, öznelliğin elde edilmesi; ${ }^{42}$ Orta Avustralya peyzajı, dijital hareketli görüntüler; ${ }^{43}$ hibrid mekânlar, korumacı/anaç mekânlar, cinsiyet rolleri ${ }^{44}$ gibi konulardır. Konulardaki bu çeşitliliğe bağlı olarak bu başlık altında bir alt gruplandırma daha yapılmıştır. Bu başlık altında film peyzajları aracılığıyla; 1) insan-insan/insan-çevre ilişkisinin değişimine dair farklı görüşler, 2) çevresel duyarlılığın artırılması-farkındalık kazanılması ve 3) cinsiyet rollerinin (ve sosyo-politik diğer açılımların) tartışııması üzerinde durulacaktır.

1) Insan- insan /insan- çevre ilişkisinin ele alınması, mesleki uygulamalarıyla çevreyi fiziksel, sosyal, görsel vb. gibi açılardan değiştiren, biçimlendiren, yeniden biçimlendiren, bunları yaparken sosyal ve algısal yönlerini de etkileyen peyzaj mimarlığı açısından özellikle önemlidir. Mumcu ve Yılmaz, ${ }^{45}$ farklı peyzajları analiz ederek, bu peyzajları oluşturan çevre ve doğaya ilişkin toplumsal yaklaşımların anlaşılmasının mümkün olacağını belirtmiş, bunların analizi için film peyzajlarını yeni bir araç olarak sunmuşlardır. Dünyanın bir ucundan diğerine farklı kültürlerin ürünleri olmaları nedeniyle filmler ve peyzajları; kıyaslamalar yapmak, yeni yaklaşımları keşfetmek, çeşitliliği sergilemek için mükemmel bir araçtırlar. Ayrıca pek çok peyzaj türü sadece belirli gruplar ve kültürler için erişilebilirdir. Örneğin okyanuslar, çöller, dağlar vb. gibi, bunlar dünyadaki bütün insanlar tarafindan tümüyle deneyimlenip anlaşılamazlar. ${ }^{46}$ Ancak film peyzajları için böyle bir sınırlama yoktur. Böylece film peyzajları aracılığıyla dolaylı yollardan da olsa bunları deneyimleme, anlama imkânı sağlanır. Farklı peyzajlara ilişkin kabuller, anlamlar ve değerler ait oldukları kültürler bağlamında anlaşılabilir. Fridh' $\mathrm{e}^{47}$ göre film; toplum, insanlar ve peyzaj hakkındaki görüşlerimizi yansıtthğından, kullanışlı bir araçtır. Fiziksel çevrenin farklı yönlerine ilişkin anlayışımız ve peyzaj hakkındaki hayal gücümüze (ve ön yargılarımız, peşin hükümlerimiz) dair farkındalığımız artar, gelişir. Böylece film, peyzaj mimarlarının tasarım yaklaşımlarını da etkiler. Bu doğrultuda bu başlık altında modernizmin insan-insan ve insan-çevre ilişkileri üzerindeki etkilerine gönderme yapan Red Desert, Lord of the Rings gibi filmler ve peyzaj yaklaşımları üzerinde durulacaktır. Bunların yanında insan-çevre ilişkisinin biçimlenmesinde temel faktörlerden biri olan, içinde yaşayanlar için peyzajın anlamı ve yorumlanması üzerinde duran Piccola Terra filmi de irdelenecektir.

Günümüzde hızla yok olan geleneksel ve kırsal peyzajlar, bunların nedenleri ve içinde yaşayan insanların bu değişimlerden nasıl etkilendiğinin anlaşılması, peyzaj mimarları için önemli bir farkındalık konusudur. Bu tür etkilere gönderme yapan filmler, bu değişim sürecinin içeriğinin

42 Pheasant-Kelly, 2013:122.

${ }^{43}$ Elwes, 2013:167

${ }^{44}$ Dempsey, 2005:119. ve dinamiklerinin anlaşılması, kavranmasında eğitsel bir araç olabilir. Red Desert (1964, yön. Michelangelo Antonioni) filmi buna örnek gösterilebilir. Gandy, ${ }^{48}$ Red Desert filmi aracılı̆̆ıyla sinematik peyzajı modernizmin çevre ve insan üzerindeki etkilerinin incelenmesi için kullanmıştır. Film, kentlerin etrafindaki kırsal alanın dramatik dönüşümüne bir ağıt olarak tanımlanır. Yabancılaşma, mekânsal olarak yönlendirilememe ve peyzajdaki renk uyumsuzluğu gibi temalar aracılığıyla teknolojik belirsizlikleri tartışır. Red Desert modern teknolojik ve kapitalist gelişimlerin sonucu olarak ortaya çıkan korku peyzajları ve umutsuzluk topoğrafyalarının incelenmesidir. Red Desert filminde kullanılan kafa karıştırıcı ve alışıımadık peyzajlar, içinde yaşayanlarda, aşina oldukları peyzajların modernizmin yıkımıyla dağıımış kalıntıları arasından geçtikçe, derin bir kararsızlık/bocalama oluşturmaktadır. ${ }^{49}$ Bu gibi kavramsal ilişkiler, peyzajın anlaşılmasında salt görsel-fiziksel olan boyutun ötesine geçebilmek için peyzaj mimarlarına firsatlar sağlarlar. Peyzajı içeren ögelerin görsel özelliklerinin ötesinde tarihi, sosyal, dini, psikolojik, davranışsal vb. gibi unsurlarla da nasıl ilişki olduklarını anlamak, peyzaj mimarlarına tasarladıkları peyzajlara çok yönlü ve daha derinlemesine bir yaklaşım geliştirebilecekleri entelektüel alt yapıyı sağlayacaktır.

Modern dünyanın getirdiği olumsuzluklar bazen bu dünyadan olmayan veya farklı bir zaman diline ait film peyzajları ile de tartışılmıştır. Tolkien'in ünlü serisi ve gişe rekorları kıran uyarlaması Lord of the Rings (LOTR, 20012003, yön. Peter Jackson) içerdiği zaman dilimi fantastik bir dünyaya ait olsa da modern sorunların tartışılmasında ve anlaşılmasında başarıyla kullanılmıştır. PheasantKelly' ${ }^{50}$ göre LOTR'de ölüm ve yıkım sürekli görünür haldedir. LOTR teknoloji ve doğa ilişkisine dayanarak ve bu ilişkiyi yansıtarak savaş, terörizm ve iklim değişikliğine dair konuları ve görüntüleri içerir. Serinin içerdiği peyzajların çoğu özünde korkutucu iken aynı zamanda öznelliği (kişisel hedefleri) elde etmeye yönelik engeller içermeleri nedeniyle umutsuzdurlar da. Başkahraman Frodo, tutarlı bir benlik duygusu kazanabilmek için bu gibi zorlukların üstesinden gelmelidir. Serideki çok sayıdaki umutsuzluk mekânına zıt olan diğer peyzajlar görkemli ve uçsuz bucaksızdır. Filmlerde mekânsal zıtlıklar genellikle düşey yönelimli olup iyiyi kötüden ayıran; genellikle kötüyü yer alt peyzajlarıyla (çok sayıda ve farklı büyüklükte mağaralar, yer alt şehirleri ve tüneller) ilişkilendiren bir duruştadır. Yıkılan yapıların dâhil edilmesi, bunun yanında uçurumların kıyılarında şiddetli ve dik düşüşlerle yukardan çekimler 9/11'i anımsatan görsel potansiyel sağlarlar. LOTR serisinde ayrıca sınırlandırılmış, kapalı mekânlara da dikkat çekilir-Rivendell, Lothlorien ya da Osgiliath gibi yerlerin hepsi diğer, farklı dünyalardan ögelerin dışarda tutulması için sı-

\footnotetext{
${ }^{48}$ Gandy, 2003:220. $\quad{ }^{49}$ Gandy, 2003:231. $\quad{ }^{50}$ Pheasant-Kelly, 2013:122.
} 
nır elemanları/engellerle çevrelenmişlerdir; biyogüvenlik ve göçle ilişkili çağdaş politik kaygılar seslendirilir. ${ }^{51}$

Modern sinema bağlamında boş alanlar ve diğer yabanıl alan sınırları, (filmdeki çeşitli ögeler aracılı̆̆ıyla gerçek hayattan bir şeyleri temsil eden ${ }^{52}$ ) alegorik kullanımla modern kentsel oluşumu dolaylı fakat provakatif bir şekilde eleştirmenin yolu olarak tanımlanmıştır. ${ }^{53}$ Yaşanılması zor yabanıl alanlar, ruhsal hayal kırıklığını temsil ederler. Bu peyzajlar filmlerde kendi başına bir karaktere dönüşmekte, filmin kahramanlarının saplantılı isteklerine karşı bir direnç geliştirmektedirler. Melbye' $\mathrm{e}^{54}$ göre bu psikolojik mücadele paradigması içinde peyzaj, bir rakip olarak Avrupa ve Amerika'nın sömürgeci politik tarihinin yeniden incelenmesi için bir arena da sunar. Bu bağlamda erkek kahraman, karakteristik olarak peyzaja karşı mücadele eden ve bu arada güce dair kendi saplantılı isteğinin sınırlarını keşfeden Batılı bir megalomandır. Aktif bir insan varlığını pek de konuksever olmayan bir peyzajla yan yana koymak ve bu yolla iç mücadeleyi tasvir etmek, sinema tarafindan kullanılan en pragmatik alegorik peyzaj aracıdır. David Lean'ın 1962 yılı yapımı Lawrence of Arabia filmi bu peyzaj alegorisi türünün erken örneğidir. ${ }^{55} \mathrm{Bu}$ tür alegorik filmler genellikle modernleşmeyi eleştirmekte ya da ruhsal kriz sahneleri yansıtmaktadırlar. Bu gibi alegorilerin en tanınmış türü Batı́nın kültürel hayal kırıklığına dair genel bir yorum yapmanın ötesine geçer ve daha korunmasız olan "Üçüncü Dünya” kültürlerinin ve doğal çevrelerinin (Orta Doğu, Güney Amerika, Afrika gibi) fethedilmesi ve sömürülmesine dair Batı'nın tarihi eğilimini ayıplar. ${ }^{56}$

Peyzajın, içinde yaşayan insanlar tarafindan yorumlanması ve anlamlandırıması üzerinde durarak, Piccola Terra (2012, yön. Michele Trentini ve Marco Romano) filmi, terk edilmiş tarım alanlarının/terasların yeniden kullanımının teşvikini amaçlar. ${ }^{57}$ Film, Brenta vadisindeki (Italya) çiftçilerin etnografik portrelerinin bir serisini sunar. Filmde anlatılan bu hikâyeler, dağılı arazinin paylaşılan fiziksel yönüne ve aynı zamanda anlamlar, eylemler ve ilişkilerden oluşan karmaşık ağına bağlanır. Filmdeki peyzajlar, filmin başkahramanları tarafindan farklı farklı görülen, algılanan, uygulanan ve paylaşılan bir mekân olarak işlev görür. Film, peyzajın çok anlamlı ve açık uçlu, mekânsal ve zamansal olarak karmaşık, açık ve hareketli, fiziksel özelliklere, kişisel öykülere ve sosyal-ekonomik bağlama dayanan bir yorumunu ortaya koymuştur. Filmin yapımı, katılımcı eylem araştırması bağlamında önemli bir uygulama olarak tanımlanmıştor. Katılımcı film, paylaşılan anlamları ortaya koymak için bir araç olarak ele alınır. Film aracılığıyla görsel-katılımcı araştırmaları yapmak; belirli konular, sorunlar ve konumlar hakkında sosyal değişimi teşvik etmek amacıyla, bilginin ve mesajların iletilmesinin bir yolu olarak kabul edilmiştir. ${ }^{58}$

\footnotetext{
${ }^{51}$ Pheasant-Kelly, 2013:138.

52 TDK, https://sozluk.gov.tr/

53 Melbye, 2006:9.

${ }^{54}$ Melbye, 2006:9.
}

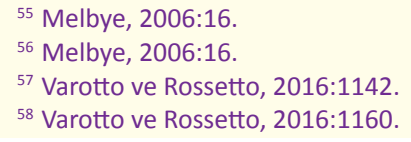

2) Çevresel duyarlılığın artırılması-farkındalık kazanılması, peyzaj mimarlığı gibi fiziksel çevreye doğrudan müdahil olan meslek grupları için özellikle aciliyet ve önem içermektedir. Çevreci-sinema, bilinçlenmeyi artırma ve eyleme geçme amaçları yanında gezegenin sağlığını etkileyen çağdaş sorunlar ve uygulamalara dair farkındalığın artırılması sorumluluğunu da üstlenir. Filmlerin büyük bir izleyici kitlesine ulaşabilmesi, yalnızca çevresel sorunlara karşı bir ilgisi olanları değil herkesi çevresel konulara dair farkındalığı tetikleyebilmesi açısından önemli bir potansiyeldir. ${ }^{59}$ Ivakhiv $^{60}$ özellikle filmlerin eğitim ve çevresel farkındalığı yükseltmek amacıyla kullanılabileceğini belirtmiştir. Bu nedenle çevreci filmler peyzaj mimarları için günümüz çevre sorunların içerdiği karmaşık ilişkileri, ekolojik süreçleri ve bileşenlerini tanımlamak, anlamak, yeni yaklaşımları öğrenmek, bakış açısını genişletmek ve farkındalığı geliştirmek için önemli bir kaynaktır. Ancak film peyzajlarının ekolojisi, içinde zenginlik ve parçalanma/çürümenin, gerçek ve gerçek dışılığın, dünyevi ve mistik olanın yana yana bulunduğu bir alan olarak nadiren araştırmalarda ele alınmaktadır. ${ }^{61}$ Ivakhiv $^{62}$ filmlerin algısal ekolojileri (filmin değerler ve kültür üzerindeki etkileri, insanlar ve dünya arasında bağ kuran felsefe ve ideolojileri) ve sosyal ekolojileri (filmin üretimi, tüketimi, yorumlanması ve kontrolüne erişime dair soruları) olduğunu belirtmiştir. Bunlar aracılığıyla pek çok soru filmlerde ele alınabilir. Tschida ${ }^{63}$ (2004) belgeseller ve çeşitli çevreci filmlerde çevre hakkındaki anlatılara odaklanmış ve hikâyelerin kullandığı metaforları tanımlamıştır. Bu doğrultuda yer ve oyuncu/aktör metaforlarını tanımlayan yazar, yer metaforunun ağırlıkta olmasını vurgular. Çevresel söylemde yer metaforunun kullanımı, coğrafik konumun benzersiz ve özel olan özelliklerini vurgulamaya çalışır. Yaygın yer metaforuna karşın alternatif metafor olarak ortaya koyulan oyuncu/aktör metaforu ise günümüzde çevresel söylemde etkin olan eko-feminizm ve derin ekoloji gibi eko-merkezli yaklaşımlarda kabul görmektedir. Oyuncu/aktör metaforunun temelinde insanlığı doğadan uzaklaştıran modern insan-merkezli ve iki kutuplu uygulamalara karşı çıkış yer alır. Oyuncu/aktör metaforu çevrenin, insanların (beyaz erkek/Avrupalılar) kendisi için tanımlamış olduğu haklar ve değerlerden daha başkalarına sahip olduğu görüşüne dayanarak doğaya saygı duyulan bir ilişkinin geliştirilmesi için işlev görebilir. ${ }^{64}$ The Woodlanders, Avatar, Lord of the Rings, The Story of the Weeping Camel, My Neighbor Totoro gibi filmleri inceleyen araştırmalar aracılığıyla, bu başlık altında film peyzajları üzerinden çevresel farkındalığa dair hangi mesajların iletildiği, ele alınan peyzajların içerdiği ögeler ve temsil ettikleri anlamlar anlaşılmaya çalışılacaktır.

\footnotetext{
${ }^{59}$ Brereton ve Hong, 2013.

${ }^{60}$ Ivakhiv, 2008.

${ }^{61}$ Harper ve Rayner, 2013:5.
} 
Cardwell'e ${ }^{65}$ göre The Woodlanders (1998, yön. Phil Agland) filminin hikâyesinde toprağı işlemekte olan işçilere vurgu yapılarak izleyiciye peyzaj üzerindeki çiftçilik ve kültür eylemleri yansıtilır. Woodland (filmde hikâyenin geçtiği kasabanın adı; ağaçık) sakinleri ile çevreleri arasındaki ilişkinin temelde simbiyotik olduğu gösterilmiştir. Bu filmde kırsal yerleşimcilerle onları ayakta tutan arazi arasında yakın ve birinci derecede önemli bir ilişki vardır. Filmde Giles karakterinin elleri ile iş yapışı, ağaçlar ve toprak ile fiziksel ilişkisi, doğaya saygısı, fidanları dikerken elma ağaçlarııı budanmış dallarına nazikçe davranırken yansıtlır. Bu durum, insan ve kırsal çevresi arasındaki sinerji olarak sunulur. İnsanlar yalnızca geçici olarak çevreyi biçimlendirmekte ve onda geçici izler bırakmakta, kalıcı bir hasar asla oluşturmamaktadırlar. Ağaçlık alana ve kırsal çevreye karşı bu saygılı tutumun kaynağında sakinlerin buraya evleri, ısınmaları, barınmaları ve yiyecekleri için bağımlı olduklarının kesin bir şekilde farkında olmaları yer alır. ${ }^{66}$

Hockenhull ${ }^{67}$ Avatar (2010, yön. James Cameron) üzerinden çağdaş çevreci söylemi tartışmıştr. Özellikli bir peyzaj estetiğini filmde konuşlandırmasıyla Cameron, izleyiciye görkemli resimsel etkiyi sağlamaktadır. İhtişamlı, azametli ve dramatik ışık kompozisyonları karşısında doğa karşısında korku ve hayret duygularını deneyimleme olarak tanımlanan görkem (süblime) çağrıştıııır. Etraflıca çevresel konuları nedeniyle takdir edilen Avatar aynı zamanda özellikle yağmur ormanları için de bir mesaj verir. Yemyeşil, oldukça büyük yaprak örtüsü, egzotik meyveler ve tropik bitki örtüsüyle ilişkili zengin toprak ve dolaylı olarak yansıttlan ekolojik kaygılar söz konusudur. Avatar izleyiciye flora ve faunanın zengin olduğu, kökleri mistisizme, geleneğe ve doğaya dayanan alternatif bir dünya sunar, bu alan görsel sanatların diğer türlerinin yansıtthklarıyla örtüşür. Görsel sanatlar da post-milenyum peyzaj kompozisyonlarına ilişkin görüntüleri ve bunun yanında hikâyeleri aracılığıyla çevre ve ekosistemlere verilen zarar için bir kaygıyı gösterir. ${ }^{68}$

LOTR serisinde görünümleri çürümüş ve iğrenç olmakla kalmayan orklar ekolojik felaketten de sorumludurlar. "Ağaçlar güçlü lordum" diyen orklara Saruman'ın cevabı "hepsini söküp çıkarın" olur; peyzajın yıkımı sahnelerine hem Tolkien okurları hem de çağdaş izleyiciler aşinadır. Orklar ağaçları Isengard'ın demirhane ocaklarının ateşi için, silahlar üretmek ve Uruk-Hai'nin oluşturulmasının teknik kısmı için kullanırlar. Özellikle Isengard ve Saruman'ın ormanın ağaçları tarafindan yok edilmesi, doğanın intikamı kavramlarıyla çok sayıda çağdaş derin yeşil, eko-merkezli yaklaşım tarafindan desteklenmiştir. Bazı sanatçılar İngiliz peyzajının endüstrileşmesini estetik bağlamda ele almışken, peyzajın yok edilmesine ilişkin Tolkien'in hikâyeleştirmesi ve Jackson'ın canlandırmaları bunu kötü

\footnotetext{
${ }^{65}$ Cardwell, 2006:27. $\quad{ }^{67}$ Hockenhull, 2013:108.

${ }^{66}$ Cardwell, 2006:30. $\quad{ }^{68}$ Hockenhull, 2013:118.
}

bir eylem olarak yansıtmakta, filmlere hâkim olan umutsuzluk mekânları aracılığıyla da bu eylemlere olumsuz çağrışım yapılmaktadır. ${ }^{69}$

St.Ours'a ${ }^{70}$ göre The Story of the Weeping Camel (2003, yön. Byambasuren Davaa, Luigi Falorni) çevreci eleştiri için gerçek bir altnn madenidir. Öncelikle toprakları ve birbirleri ile ilişkilerini, ekolojik sürdürülebilirlik etiği ile tanımlayan bir halkın benzersiz doğa/etnografik açıklamasıdır. İkinci olarak film, göçebe bir halkın hayvanlarıyla birbirlerine karşılıklı bağımlılığını, yaşamlarını sürdürebilmeleri için bağımlı oldukları doğal çevreye oturtur ve çağdaş teknolojik toplumun geleneksel yaşam şekillerine etkisini sorgular. Başlangıcından itibaren doğa karşısında alçakgönüllülük ve saygılı bir tutum iletir. Belgesel boyunca yerin kutsallığı, çevreleyen manzaranın (çölün kendisi, gündoğumu, gün batımı ve yaklaşan kum firtınası) uzun panoramik çekimleriyle ve zaman aracılığıyla vurgulanmıştır. Bunların hiçbirinde insan ya da hayvanlar yoktur. Göçebelerin çevreyi kendilerine mal etmedikleri vurgulanmıştır. Göçebeler doğayla uyum içinde yaşamaya çalışmaktadırlar. Film aracılığıyla doğal çevreyi hem küresel hem de yerel bağlamda korumaya dair sorumlulukların daha güçlü bir anlayışına erişilir. ${ }^{71}$

Japonların tüm dünyada popüler bir kültürel tüketim aracı olan animasyon filmleri- animeler, Japon kültürünün içerdiği insan-çevre ilişkisinin, Bat düşüncesine önemli karşıtlıklar sergilemesi nedeniyle sıklıkla çevreci söylem kapsamında değerlendirilmektedirler. Anime, Hollywood animasyonlarının birbirinden kopuk insan-çevre kavramlarını benimseyen Kartezyen iki kutupluluğunda bir kırılma oluştururken ${ }^{72}$ karmaşık hikâye akışlarıyla Disney'in öngörülebilirliğine alışkın olan izleyiciyi zorlar. Bu nedenle $\mathrm{Napier}^{73}$ animeyi "güvence"den ziyade "güvensizlik-kuşku" sineması olarak tanımlamıştır. Sunduğu daha kışkırtıcı ve trajik dünyalar ile animeler izleyiciyi harekete geçirmekte ve uyarmaktadırlar. ${ }^{74}$ Stokrocki ve Delahunt ${ }^{75}$ animelerin ekolojik sürdürülebilirlik gibi temel yaşamsal konuların tartışılmasını motive edebileceğini öne sürmüşlerdir. Yokohari ve Bolthouse ${ }^{76}$ My Neighbor Totoro (1988, yön. Hayao Miyazaki) filminin Satoyama (geleneksel Japon) peyzajlarının korunmasına dair kamusal kaygınının yükseltilmesinde nasıl güçlü bir rol oynadığını açıklamışlardır. Batılı animasyonlardan bu önemli farklııkları ile anime yaygın insan-çevre ilişkisinin ötesine geçen bir anlayışın geliştirilmesine katkıda bulunabilir, karmaşık insan-çevre ilişkisinin ve çevresel sorunların peyzaj mimarları tarafindan anlaşııması için uygun bir araç olabilir. ${ }^{77}$ Bu başlık altında ele alınan filmler, içerdikleri peyzajlar ve hikâyelerinde insanların peyzajla

\footnotetext{
${ }^{69}$ Pheasant-Kelly, 2013:141.

${ }^{70}$ St. Ours, 2011.

${ }^{71}$ St. Ours, 2011.

72 Tomos, 2013.

73 Napier, 2001.
}

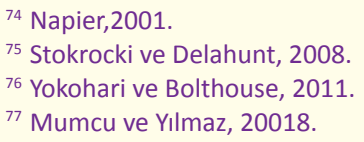


girdikleri etkileşimler üzerinden, insan ve çevrenin karşılıklı ilişkisini, insanların çevreye/doğaya karşı sorumluluklarını, artan çevresel kaygıyı işlemektedirler. Bu bağlamda film peyzajları, peyzaj mimarlarının çağdaş çevresel sorunlar ve uygulamalara dair farkındalıklarının artirılması, tasarımlarının sonuçlarına dair sorumluluklarının farkına varmaları, ekosistemin içerdiği birbirine bağımlılığı ve süreçleri anlamaları gibi işlevleri üstlenebilirler.

3) Peyzajlar aracılığıyla cinsiyet rollerinin tartışılması hem toplumsal yapıların sosyal ve politik katmanlarının hem de cinsiyet rollerine paralel olarak oluşan mekânsal kullanım, anlam, değer gibi kavramların daha iyi anlaşılmasına katkı sağlar. Film peyzajı; cinsiyet, mekân ve yer bağlamında sosyo-politik söylemin simgesel alanı olarak tanımlanmaktadır. ${ }^{78}$ Bu bağlamda doğal dünya ve kadın arasında kurulan bağ filmlerde sıklıkla karşımıza çıkar. Dempsey ${ }^{79}$ doğal dünyanın fethedilmesi/işlenmesi gereken bir şey gibi görülmesi doğrultusunda doğa ve kadın arasında birinden diğerine geçen bir kod çevrimi olduğunu belirtir. Böylece her ikisi de erkeğin yüklediği anlamın yükü altına girmekte ve erkeklik söyleminin yorumuna maruz kalmaktadır. Kadın figürünün peyzajı, peyzajın da kadın figürünü temsil ettiği, her ikisinin de pasiflik ve durağanlıkla ilişkili aynı topoğrafyayı paylaşthğı düşünülmektedir. ${ }^{80}$ Tersi şekilde kentsel, endüstriyel alanlar, değişim peyzajları erkeklik ile ilişkilendirilir. Örneğin Like Father (2001, yön. Richard Grassick, Ellin Hare, Sirkka-Liisa Konttinen, Murray Martin) filmi aracılığıyla Doğu Durham'ın kömür madenleri sonrasındaki peyzaj içerisinde erkeklik, yıkım sahneleri ve değişim peyzajları ile somutlaştrılmaktadır. Filmin kahramanı baba Arthur, değişen peyzajın erkeklik rolleri üzerindeki etkisine dair görsel ve sözel bir hikâyedir. ${ }^{81}$

Dempsey $^{82}$ ele aldığı filmler üzerinden yaptı̆ı analizlerde kadın kahramanların "korumacı/anaç mekânlar" ve yerler yaratarak erkeklik düzenini altüst ettiği "korumacı/anaç film" türünü ele almıştır. Bu filmlerde anaçlık sadece kadın karakterlerle değil, doğanın kendisiyle de ilişkili kılınmıştır. Bu ikisi arasındaki etkileşim, öykünün gidişatında merkezi konumdadır. Sanki yayılmakta olan kent, bu feminen sinematik peyzajları, ataerkil görüş alanının sınırına itmişçesine bu peyzajlar Amerika sınırlarının yakınlarındaki kırsal alanlarda var olurlar. Bu filmlerdeki kadınlar, doğanın anaç gücüne ve baskın kültür tarafindan dışlananların yardımına hizmet etmekte, beyaz erkeğin şiddetini yok edebilecekleri mekânlar üretmektedirler. Böylece farklılığı temsil eden ve ona ses veren, kutlayan yenilikçi-ilerici mekânlar oluşturulmaktadır. Başka bir deyişle kadın kahramanlar hibrid/ melez mekânlar oluşturmaktadırlar. Kendilerini görünmez kabul eden beyaz üst-sınıf erkek kültüründen ayrı, koruyucu bir toplumu oluşturup pekiştirebilecekleri canlı bir

\footnotetext{
78 Dempsey, 2005:116.

${ }^{79}$ Dempsey, 2005:116.
}

peyzaj da bu filmlerde sergilenir. Places in the Heart (1984, yön. Robert Benton), The Spitfire Grill (1996, yön. Lee David Zlotoff) filmleri bu filmlere örnek olarak gösterilmiştir. ${ }^{83}$ Bu gibi film okumaları hem toplumsal cinsiyet rollerinin anlaşılmasına hem de bu rollerin mekânlara ve özellikle peyzaja nasıl yansıtıldığına dair farkındalık kazandırmaktadır. Böylece film okumaları aracılığıyla film peyzajları, peyzaj mimarları için toplumsal anlamların, değerlerin inşası, simgeleştirilmesi, mekânla ilişkilendirilmesi gibi konularda etkili bir öğrenme ve farkındalık kazanma aracı olabilir. Bu yolla peyzaj mimarlarının yaptıkları tasarımlar aracılı̆ıyla toplumsal sorunlara çözüm geliştirmeleri, dezavantajlı gruplar için çevresel koşulları iyileştirmeleri beklenebilir.

Filmlerdeki Peyzajların Peyzaj Mimarlığı/Mimarlık Eğitiminde Bir Araç Olarak Kullanılması

Bu başlık altında filmlerin peyzaj mimarlığı eğitiminde tasarım stüdyolarında bir araç nasıl olarak kullanılabileceği ve yapabilecekleri katkılar çeşitli araştrrmalar aracılığıyla tartışılmıştr. Dee'ye ${ }^{84}$ göre film peyzajları, peyzajın zamansal, süreçsel, kurgu ve insani dramatik yönlerini anlamak ve incelemek üzere kullanılabilir. Örneğin; açık mekânlarda gerçekleşen sosyal hayata ilişkin öyküler aracılığıyla insan ilişkilerinin hikâyesini incelemek bu araştırmaların kapsamındadır. Peyzaj ve ekolojik süreçlere ilişkin görsel hikâyeler/filmler ile bu süreçler ve bunların içinde nasıl tasarım yapılacağı daha fazla anlaşılabilir olabilir. Dee ${ }^{85}$ ayrıca yazılı araştırmaların özellikle içine dâhil olamadığı konular olduğunu, görsel olarak araştırmalar yapmanın üçüncü boyutla bütünleşmeyi sağladığını belirtir. Bu, kelimelerin kâğıt üzerinde yapamayacağı şekilde bağlantıların kurulmasını teşvik ederek yeni fikirler ortaya çıkartır. Görsel olarak araşttrma yapmak, düşüncede üçüncü boyutu uyarır ve tetikler. ${ }^{86}$

Fridh, ${ }^{87}$ "film bir araç olarak mekânın ve tasarımının anlaşımasını tanımlamak, yorumlamak ve yönlendirmek için nasıl kullanılabilir ve tasarım sürecinde peyzaj mimarlı̆̆ının hangi yönlerini vurgular?" gibi sorularla film ve peyzaj tasarımı arasındaki bağı sorgulamıştır. Peyzaj mimarlığı bağlamında filmin bir eğitim aracı olma potansiyelini sorgulayan nadir çalışmalardan biri olan bu çalışmada, yönetmen Ingmar Bergman filmleri üzerinden geleneksel İsveç peyzajı ve modernizmin etkileri anlaşımaya çalışılmıştır. Daha sonra mimar Bruno Mathsson'un “Cam Evi”nde yapthğı film çekimleri ile araştırmacı, modern yapıların çevreleyen peyzajla ve insanlarla ilişkisini sorgulamış ve anlamaya çalışmıştır. Filmin planlanacak ve tasarlanacak bir çevreye yaklaşım sürecinde faydalı bir araç olduğu; farkındalığı artırarak, çevreye ilişkin daha karmaşık bir görünümü benimsettiği belirtilmiştir. ${ }^{88}$

\footnotetext{
${ }^{83}$ Dempsey, 2005:129, 133.

${ }^{84}$ Dee, 2004:24-25.

${ }^{85}$ Dee, 2004:2).

${ }^{86}$ Dee, 2004:5.

${ }^{87}$ Fridh, 2006:4.

${ }^{88}$ Fridh, 2006:70.
} 
Öğrencilerin mekânların çevresel kaliteleri ile insanların bilişsel-algısal sistemleri arasındaki ilişkiyi anlamalarını geliştirmek amacıyla bazı araştırmacılar mimarlık ve kentsel tasarım stüdyolarında sinema tekniğine dayalı bir öğrenme yöntemi önermişlerdir. ${ }^{89-91}$ Çalışmalarında yaptıkları uygulama aracılığıyla öğrenciler sinematik senaryo kurgulamanın, tasarım sürecinin nasıl parçası olduğunu ve final projelerini bir film olarak nasıl sunabileceklerini öğrenmişlerdir. Aminzadeh ve arkadaşları ${ }^{92}$ peyzajın da görsel ve mekânsal bir hikâye olduğu kabulüyle filmlerin senaryoları bağlamında peyzaj tasarımıyla ilişki kurmuştur. Kavram, analiz, tasarım ve detay gibi safhalarda peyzajın hikâyesinin planlanmasının, sinemadaki senaryo yazım sürecine benzediğini belirtmişlerdir. Bir peyzaj içinde harekete ve hareket halindeyken edinilecek deneyimlere dair bir senaryo, sinemadaki senaryo yapısına benzer. Sinemadaki dramatik hikâyeler; macera, olay, konu detayları, kırılma anları, başlama ve bitiş noktaları içerir. Bunlar peyzaj tasarımının bileşenleri ile kıyaslanabilirler. Sinematik teknik, mekânların ve olayların art arda dizilimi ile kullanıcılarda zaman ve hareket farkındalığı oluşturmaktadır. Bu, kullanıcıların aynı kent mekânını tamamen farklı şekillerde deneyimlemesine sebep olabilir. Bu kabullerden yola çıkarak peyzaj deneyimindeki monotonluğun azaltılması ve konumdaki çeşitli memnuniyet verici manzaraları ve vistaları vurgulayarak, peyzajda art arda gelen mekânların dramatik çekiciliğinin artrılmasını hedefleyen bir çalışma yürütülmüştür. Yürütülen çalışmada ele alınan alan ardışık sahneler halinde görselleştirilerek peyzaj özellikleri analiz edilmiş, yine film sahnelerine benzer şekilde ardışık sahneler halinde görselleştirmeler yapılarak tasarım önerileri geliştirilmiştir. Çalışma sonucunda dramdaki senaryo yazım tekniklerine yönelerek, tasarım konumun fiziksel analizlerine bağlı olarak uygulanacak hikâyenin daha anlamlı öykülerle yer değiştirebileceği belirtilmiştir. ${ }^{93}$

Filmin bir eğitim aracı olarak kullanılmasının en somut örneği İngiltere, Sheffield Üniversitesi'nde bir proje kapsamında gerçekleştirilmiştir. ${ }^{94}$ Yerin daha kapsamlı bir şekilde anlaşılmasının ve okullarda görsel okumanın, çocukların televizyon, sinema, bilgisayar, oyunlar, internet erişimi ve mobil telefon kullanımıyla görsel medyayı kapsamlı bir şekilde kavramasını sağladığı, bunun da aşinalık ve çeşitlilikle görsel okuma yeteneklerini güçlendirdiği öne sürülmüştür. Projedeki etkinlikler kentin gösteriminin yer aldığı bir filmin (Sheffield, City on the Move, 1971, yön. Jim Coulthard) izlenmesi ile başlamıştır. Fiziksel mekânların ve tekniklerin (kamera açıları ve düzenleme türleri gibi) tanınması ve tartş̧ılmasından sonra kentin imgesini güçlendirecek ve güncelleyecek bir grup görevi oluşturulmuştur. Bu görev

\footnotetext{
${ }^{89}$ Stickells ve Mosley, 2008.

90 Pizzaro, 2009.

91 Pizzaro, 2011.
}

\footnotetext{
${ }^{92}$ Aminzadeh ve ark., 2016:179.

${ }^{93}$ Aminzadeh ve ark., 2016:188.

${ }^{94}$ Forrest ve Rayner, 2013:201.
}

çocukların kentteki favori ya da en önemli buldukları konumları gösteren bir filmin hayal edilmesi ve hazırlanmasını içerir. 40 yılı aşkın geçmişe sahip olan filmin gösterimiyle kentin geçirdiği değişim bağlamında çocuklar aşina oldukları mekânlar ve yerleri aşina olmadıkları bir görsel çevre içinde (yapılar, araçlar, kıyafetler, saç modelleri ve film türü gibi dönemin göstergeleri nedeniyle) görmüşlerdir. Bir zamanlar tanıdık ve uzak olan bir Sheffield hikâyesini izleyerek, çocuklarda tanıma ve yerini yadırgama arasında bir gerilim oluşmuştur. Bu gerilimin, çocukların kentlerini nasıl okuduğunun ve bunu takiben kentin imgelerini nasıl yapılandırdığının incelenmesi için verimli bir platform oluşturduğu belirtilmiştir. ${ }^{95}$ Benzer uygulamalar peyzaj mimarlığı öğrencileri için de çeşitli yararlar sağlayabilir; görsel okuma ve mekâna ilişkin deneyimlerin senaryolaşttrılması yanında bir kent mekânın geçmişten günümüze içerdiği işlevler, anlamlar ve değerlerin değişiminin anlaşılması, bir kent mekânında yer ve kimlik duygusunun bileşenlerinin tanımlanması vb. gibi.

Bazen de film ve kent mekânı arasındaki ilişkilerin algısal boyutu vurgulanmıştır. Kamera, statik yapıyı çözmeye başlayıp, mimari formlar, mekânlar ve elemanlara hareket kazandırdığında, sinemanın kendisi mimariye dönüşür. ${ }^{96}$ Ding ${ }^{97}$ bu algısal boyutu, iki boyutun ifade etmekte yetersiz kaldığı üçüncü ve dördüncü boyut kentsel mekân sorunu üzerinden ele almıştir. Kentsel mekânsal algı, mekân içerisindeki harekete ve değişen görünümlere bağlı olduğundan, kentsel mekân statik bir mekân değildir. Mekâna ilişkin mevcut araştrrma yöntemleri çoğunlukla iki boyutlu ya da üç boyutlu Kartezyen koordinat sistemine dayanan klasik tekniğe bağımlıdır. Mevcut çizim yöntemleri hem yatay hem de dikey ara yüzleri tek bir harita üzerinde birleştirememektedirler. Oysa insanların kent mekânını dinamik halde algısı dört boyutludur ve karakteristikleri mekân ve eylemin birleşimidir. İnsanlar dört boyutlu mekânı sadece değişen görüntüler aracılığıyla deneyimleyebilirler. Teknik bir yöntem olarak sinematografi; yani görüntüler kaydedilirken ışıklandırma, kamera ve hareket seçeneklerinin bir araya getirilme şekli, kentteki fiziksel mekânı, insanlar ve objelerin zaman içindeki değişimlerini doğrudan kaydeder. Işıktaki değişimler birleşerek manzara, konum ve zamanı oluşturur. Sonuç olarak sinematografi, kentin mekânsal karakteristiklerinin kaydedilmesi için en etkin yöntemdir; kent mekânında zaman duygusunu ortaya koyar. Ekran üzerindeki grafik değişimlerin izlerini incelemenin insan algısındaki kent mekânının haritalanması için bir yöntem olabileceği belirtilirken, sinematografi yapıların temsil edilmesine yardımcı olabilir ve mimari ve kent araştırmalarına katkıda bulunabilir. ${ }^{98}$ Bu katkıları filmi mekânsal karakteristiklerin oluşumlarının ve zamanın etkisinin daha iyi anlaşıl-

\footnotetext{
${ }^{95}$ Forrest ve Rayner, 2013:203.

${ }^{96}$ Weihsmann, 2011:40.
} 
ması bakımından peyzaj mimarları ve öğrencileri açısından da kullanışlı bir araç yapar. Hareket, açı, mekân gibi özellikleri öğrenebilirler. Özellikle zaman peyzajda en önemli bileşen olduğu halde etkilerinin öngörülmesi zor olan bir faktördür. Filmler aracilı̆ı̆yla zaman-mekân ilişkisini anlamak daha mümkün olur.

Film peyzajları, içerdikleri ögelerin gerçek hayattaki unsurları nası ilişkili olduklarının/alegorilerin ele alınmasıyla da tasarımlara katkıda bulunabilirler. Melbye, ${ }^{99}$ izleyicilerde filmlerdeki peyzaj alegorisine ilişkin bir farkındalık geliştiğinde, film kahramanlarının psikolojik boyutları ile bunların dış dünyaya yansımasındaki örtük ilişkinin anlaşılabileceğini öne sürer. Böyle bir anlayışın izleyiciyi eğittiğini de belirtmiştir. Peyzaj karakterlerinin yüklendiği anlamların anlaşılması, kavramsal tasarımlarda bir anahtar, ilham kaynağı olarak kullanıımalarını mümkün kılar. Böylece tasarımların anlamsal boyutları zenginleştirilebilir, senaryolar daha yaratıcı ve ilginç kılınabilirken, öğrencilerin kültürel farklııklara karşı da duyarlıığı artırabilir. Örneğin; filmlerde yer alan bir çölün labirentimsi çizgileri, insan ruhunun manevi karmaşıklığını, çöl ya da boş arazilerin ruhsal hayal kırıklığını yansıtabilmesi, bir nehir yolculuğunun varoluşsal gerçeğe doğru bir rotayı, bir çeşit psikolojik dönüşümü ima edebilmesi gibi. ${ }^{100}$ Bu tür anlamlara dair görsel okumanın güçlendirilmesi ve projelerin kavramsal tasarımlarına yansıtılmasının beklenmesi, peyzaj mimarlığı öğrencilerinde yaratıcılığı teşvik eden, özgün fikirlerin üretilmesini kolaylaştran bir uygulama olabilir.

\section{Sonuç}

Bu araştırma, filmin ve peyzajlarının peyzaj mimarlığı açısından sahip olduğu potansiyelin yeterince kullanılmadığı varsayımından yola çıkmıştır. Film peyzajlarının, peyzaj ve mekân kavramının anlaşılması ve derinleştirilebilmesi için potansiyel kullanımlarının tanımlanması amaçlanmıştir. Yeni bir eğitim ve araştırma aracı olarak potansiyel değerinin ortaya koyulması da çalışmanın diğer amacıdır. Benzer bakış açısıyla Fridh, ${ }^{101}$ filmin bir araç ve eylem olarak farklı peyzaj koşullarına ilişkin bilgi birikiminin ve anlayışın derinleştirilmesi için iyi bir araç olduğunu belirtmiştir. Harper ve Rayner, ${ }^{102}$ film peyzajlarının sadece kültürel tarihle değil politik amaçlar ve daha geniş bir bağlamla da ilişkili olduğunu belirtmiştir. Bu çalışma kapsamında ele alınan araştırmalarda film peyzajları aracılığıyla tartışılan konuların çeşitliliği oldukça zenginlik sergilemiştir. Film peyzajları hayata dair tüm konuları ve yeryüzündeki tüm halklar, kültürleri ve çevrelerini kapsayabilmektedir. Bu nedenle benzersiz bir düşünsel araç olma potansiyeli sergilerler. Ayrıca bu çalışmalardan çıkartılacak bir başka sonuç da hiçbir zaman sadece fiziksel-coğrafi bileşenlerden

99 Melbye, 2006:204.

100 Melbye 2017:112.

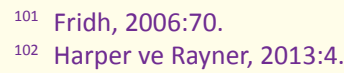

ibaret bir peyzajın ele alınmadığıdır. Peyzajı tartş̧an tüm araştırmacılar, film karakterlerini hem ruh halleri ve eylemleri ile birlikte ele almış ve peyzajı da bunlarla birlikte tanımlamıştır. Bu durum insan ve çevre kavramın ayrı ayrı ele alınamayacağını, peyzaj tasarımcılarının asıl görevinin salt peyzaj bileşenlerini tanımlamak değil insan kullanımı ve deneyimlerini de tanımlamak olduğunu gösterir. Peyzaj mimarları için bu, insan-insan ve insan-çevre ilişkisinin fiziksel çevre boyutundan öteye bir anlayışın gerekliliğini ortaya koyar. Böyle bir farkındalığın gelişmesi ve peyzaj tasarımın içerdiği kavramsal karmaşıklığın ve ilişkiler ağının daha iyi kavranması anlamına gelebilir. Dee ${ }^{103}$ de peyzaj mimarlığında görüntülerin esasen tasarımları temsil etmek ve geliştirmek için bir teknik olarak kullanıldığı, peyzajların kendi başına sosyal, felsefi ve kültürel boyutlarını incelemek ve araştırmak için daha az kullanıldığı şeklinde eleştirmiştir. Tüm bu eleştiriler ve bulgular film peyzajlarının peyzaj mimarları için potansiyel bir eğitim aracı olabileceğini ortaya koymaktadır. Film peyzajları ayrıca ait oldukları dönemin siyasi-politik-kültürel yönlerinin ve bunların peyzajlar üzerinde nasıl etki bıraktığının da daha iyi anlaşılmalarını sağlarlar. Böyle bir anlayış ise günümüzde etkin olan faktörleri ve bunların olası sonuçlarını daha iyi tahmin etmeyi ve gerekli hamleleri tanımlayabilmeyi sağlar. Bunlar dışında film peyzajlarının eğitim aracı olarak kullanıldığında tasarım stüdyosu bağlamında; senaryo ve kavramsal tasarım, mekânsal bileşenlerin ve bir araya gelişlerinin oluşturduğu mekânsal karakterin üç boyutlu hayal edilmesi; mekân-zaman, mekân-hareket, mekân-bakış açısı gibi ilişkilerin kurgulanmasına katkıda bulunabileceği ortaya koyulmuştur.

Belirtilen bu potansiyelleri doğrultusunda filmler peyzaj mimarlığı eğitim faaliyetlerinde şu şekillerde kullanılabilirler:

- Öğrencilerin öncelikle görsel okuma konusunda bilgilendirilmesini takiben, öğrencilerden film peyzajları aracılığıyla farklı kavramları (yazılı ödevler, çizimlereskizler, sınıf içi tartş̧malar aracılığıyla) yorumlamaları istenilebilir, böylece peyzajın çok yönlü yapısını daha derinlemesine anlamaları sağlanabilir.

- Öncesi-sonrası uygulamaları ile (anket, görüşme, sınıf içi tartş̧malar gibi tekniklerle) filmlerin oluşturduğu etkiler, farkındalık seviyelerindeki değişimler ele alınabilir ve çeşitli konularda öğrencilerin farkındalıklarını geliştirmek mümkün olabilir.

- Yine filmlerdeki kavramları ve ilişkilerin yorumlanmasını takiben bunların tasarım yaklaşımları ve senaryolarına yansıtılmasına dair tasarım stüdyosu uygulamaları yapılabilir.

- Film sahneleri üzerinden peyzaj ve mimari bileşenlere dair analizler yürüterek (çizimler, içerik analizler

\footnotetext{
103 Dee, 2004:14
} 
gibi teknikler ile) üç boyutlu düşünme ve mekânın algılanması konusunda gelişmeleri sağlanabilir, farklı mekânsal karakteristiklerin bileşenlerini anlamaları desteklenebilir.

- Yukarıda belirtilen uygulamalardan farklı olarak öğrencilerin film yapım teknikleri (kamera açısı, ışık ayarları, hareket yönü vb. gibi) hakkında bilgilendilmelerini takiben öğrencilere belirli konular ya da alanlar hakkında senaryo, sahne ve/veya film hazırlama görevi verilerek, insan-mekân etkileşimine dair farklı boyutların ya da mekânda zaman, bakış açısı ve hareketin algılanması konularında gelişmeleri sağlanabilir.

Mimarlıktan coğrafyaya ve kültürel çalışmalara film peyzajlarına olan bilimsel ilgi yaygınlaşmakta ve bu konudaki çalışmalar hızla artmaktadır. Çalışma kapsamında ele alınan film araştırmaları kronolojik olarak bir araya getirildiğinde (Napier, 2001; Gandy, 2003; Tschida, 2004; Dempsey, 2005; Cardwell, 2006; Melbye, 2006; Stokrocki ve Delahunt, 2008; St.Ours, 2011; Bertellini, 2012; Elwes, 2013; Forrest ve Rayner, 2013; Hockenhull, 2013; Pheasant-Kelly, 2013; Varotto ve Rossetto, 2016; Mumcu ve Yılmaz, 2018 vb. gibi) araştırmaların $2000^{\prime}$ li yıllardan itibaren giderek artmakta olduğu görülür. Peyzaj mimarlığı da bu çalışma alanın bir parçası olmalı ve peyzaj mimarlığında film peyzajlarına ilişkin araştrmalar temel alanlardan birisine dönüşmelidir. ${ }^{104}$ Bu bağlamda peyzaj mimarlığı eğitim-öğretim programlarının film okumaları ve peyzajlarına dair gerekli teorik ve uygulama bileşenleri ile desteklenmesi sağlanmalıdır. Bunlar seçmeli dersler şeklinde olabileceği gibi bazen de tasarım stüdyoları içinde uygulamalar olarak yürütülebilirler.

Son olarak bu çalışmada yer verilen film araştırmaları ve ele aldıkları filmler; türleri (sinema, belgesel, animasyon vb. gibi), konu türleri (western, aksiyon, macera, drama, fantazi vb. gibi) ya da yapım teknikleri (gerçek peyzaj çekimleri, kurgu peyzajlar gibi) bakımından herhangi bir sınıflandırma yapılmaksızın ele alınmışlardır. Ancak bu gibi farklııklar, gerek filmlerin izleyicilerde uyandırdıkları izlenimler gerekse mekân-zaman, mekân-hareket ilişkisinin algılanması gibi etkileri bakımından peyzaj mimarlığı araştormalarında ve tasarım stüdyosu uygulamalarında dikkate alınmalıdır. Bu nedenle, gelecek çalışmalarda çalışmanın amacı ve ne tür bir yöntem uygulanacağına bağlı olarak ele alınan filmlerin sınıflandırılması göz ardı edilmemelidir.

\section{Kaynaklar}

Aminzadeh, B., Motevaliand, M., ve Nikooparast, S. (2016) "A proposal for landscape design process based on scenario writing phases in cinema and its application in the Darabad", Urban Design International, Sayı 21:2, s.175-189

Avrupa Birliği (2004) "European Landscape Convention-Expla-

104 Mumcu ve Yılmaz, 2018. natory Report", https://rm.coe.int/16800cce47 [Erişim Tarihi on 8 Mart 2018].

Bertellini, G. (2012) “The Earth Still Trembles: On Landscape Views in Contemporary Italian Cinema", Italian Culture, Sayı 30:1, s.38-50, doi:10.1179/0161-4622112.0000000002.

Bigell, W. ve Chang, C. (2014) "The Meanings of Landscape: Historical Development, Cultural Frames, Linguistic Variation, and Antonyms", Ecozon@, Sayı 5, s.84-103.

Brereton, P. ve Hong, C., P. (2013) "Audience responses to environmental fiction and non-fiction films", Interactions: Studies in Communication \& Culture, Sayı 4:2, s.171-199 doi: 10.1386/iscc.4.2.171_1

Bruno, G. (2002) Atlas of Emotion. Journeys in Art, Architecture, and Film. New York: Verso.

Cardwell, S. (2006) "Working the Land Representations of Rural England in Adaptations of Thomas Hardy's Novels", Editörler: Gillian Helfield ve Catherine Fowler, Representing the Rural: Space, Place, and Identity in Films about the Land, Wayne State University Press, s.19-34.

Christie, I. (2000) “Landscape and 'Location': Reading Filmic Space Historically", Rethinking History, Sayı 4:2, s.165-174.

Curti, G., H. (2008) "The ghost in the city and a landscape of life: A reading of difference in Shirow and Oshii's Ghost in the Shell", Environment and Planning D: Society and Space, Sayı 26, s.87-106

Dee, C. (2004) “'The Imaginary Texture of the Real ...' Critical Visual Studies in Landscape Architecture: Contexts, Foundations and Approaches", Landscape Research, Sayı 29:1, s.13-30.

Dempsey, A. (2005) “Nurturing Nature and Cinematic Experience: The American Landscape and the Rural Female Community", Journal of Cultural Geography, Sayı 23:1, s.115-137, doi: 10.1080/08873630509478234.

Ding, W. (2011) "Mapping Urban Space: Moving Image as a Research Tool", Editörler: François Penz ve Andong Lu, Urban Cinematics Understanding Urban Phenomena through the Moving Image, Intellect, s.257-279.

Dissanayake, W. (2010) "Landscapes of meaning in cinema: Two Indian examples", Editörler: Graeme Harper ve Jonathan Rayner, Cinema and Landscape, Bristol: Intellect, s.189-202.

Eisenstein, S. (1987) Nonindifferent nature. Cambridge, UK: University of Cambridge Press.

Elwes, C. (2013) “Figuring Landscapes in Australian Artists' Film and Video", Editörler: Jonathan Rayner ve Graeme Harper, Film Landscapes: Cinema, Environment and Visual Culture, Cambridge Scholars Publishing, s.164-182.

Fish, R. (2014) Cinematic Countrysides "Landscape embodied Introducing Like Father", Manchester University Press.

Forrest, D. ve Rayner, J. (2013) “"Sheffield Film Studies and Sheffield Studies Film": The Cinema and Landscape Project", Editörler: Jonathan Rayner ve Graeme Harper, Film Landscapes: Cinema, Environment and Visual Culture, Cambridge Scholars Publishing, s.199-215.

Fridh, S. (2006) "Filmiska landskap-film som representation, verktyg och handling i landskapsarkitektur (İsveçce) (Filmic landscapes-film as representation, tool and practice in landscape architecture)", Basılmamış Bitirme Tezi, Peyzaj Mimarlığı Programı, Peyzaj Planlama Bölümü, Swedish University of Agricultural Sciences. 
Gandy, M. (2003) "Landscapes of deliquescence in Michelangelo Antonioni's Red Desert", Transactions of the Institute of British Geographers, Sayı 28:2, s.218-237.

Greider, T. ve Garkovich, L. (1994) "Landscapes: The Social Construction of Nature and the Environment", Rural Sociology, Sayı 59, s.1-24.

Harper, G. ve Rayner, J. (2013) “Introduction”, Editörler: Jonathan Rayner ve Graeme Harper, Film Landscapes: Cinema, Environment and Visual Culture, Cambridge Scholars Publishing, s.1-8.

Hockenhull, S. (2013) "An Age of Stupid?: Sublime Landscapes and Global Anxiety Post-millennium" Editörler: Jonathan Rayner ve Graeme Harper, Film Landscapes: Cinema, Environment and Visual Culture, Cambridge Scholars Publishing, s.106-120.

Ivakhiv, A. (2008) "Green Film Criticism and Its Futures", Interdisciplinary Studies in Literature and Environment, Sayı 15, s.1-28.

Jazairy, E. H. (2009) "Cinematic landscapes in Antonioni's L'Avventura", Journal of Cultural Geography, Sayı 26:3, s.349367, doi: 10.1080/08873630903322262

Lefebvre, M. (2011) "On landscape in narrative cinema”, Revue Canadienne d'Études cinématographiques/Canadian Journal of Film Studies, Sayı 20:1, s.61-78.

Lukinbeal, C. (2005) "Cinematic Landscapes", Journal of Cultural Geography, Sayı 23:1, s.3-22, doi: 10.1080/08873630509478229

Melbye, D. (2006) "The Contemplative Landscape: Allegories of Space in Cinema", Basılmamış Doktora Tezi, Faculty of the Graduate School, University Of Southern California.

Melbye, D. (2017) "Psychological landscape films: narrative and stylistic approaches", Aniki, Sayı 4:1, s.108-132. doi:10.14591/aniki.v4n1.267

Moran, A. (2006) "Migrancy, Tourism, Settlement, and Rural Cinema", Editörler: Gillian Helfield ve Catherine Fowler, Representing the Rural: Space, Place, and Identity in Films about the Land, Wayne State University Press, s.224-239.

Mumcu, S. ve Yılmaz, S. (2018) "Anime Landscapes as a Tool for Analyzing the Human-Environment Relationship: Hayao Miyazaki Films", Arts, Sayı 7, Bölüm 16, doi:10.3390/ arts7020016.

Napier, S. (2001) Anime from Akira to Howl's Moving Castle: Experiencing Contemporary Japanese Animation, New York: Palgrave Macmillan.

Pandian, A. (2011) "Landscapes of Expression: Affective Encounters in South Indian Cinema", Cinema Journal, Sayı 51:1, s.50-74.

Pheasant-Kelly, F. (2013) "Landscape, Spectacle and Subjectivity: Abject spaces in Peter Jackson's the Lord of the Rings trilogy", Editörler: Jonathan Rayner ve Graeme Harper, Film Landscapes: Cinema, Environment and Visual Culture, Cambridge Scholars Publishing, s.121-145

Pizarro, R.E. (2009) "Teaching to Understand the Urban Sensorium in the Digital Age: Lessons from the Studio", Design Studies, Sayı 30:3, s.272-287.

Pizarro, R.E. (2011) "Urban design and the cinematic arts", Editörler: T. Banerjee ve A. Loukaitou-Sideris, Companion to Urban Design, London and New York: Routledge, s.208-217.

Saunders, F. P. (2013) "Seeing and Doing Conservation Diffe- rently: A Discussion of Landscape Aesthetics, Wilderness, and Biodiversity Conservation", The Journal of Environment Development, Sayı 22, s.3-24.

St.Ours, K. (2011) "An Ecocritical Study of The Story of the Weeping Camel", Interdisciplinary Studies in Literature and Environment, Sayı 18:2, s.396-412.

Stickells, L. ve Mosley, J. (2008) "Imaginary Construction: Filmic Processes within the Architectural Design Studio", International Design and CinemaConference, 19-22 November, Istanbul. http://eprints.uwe.ac.uk/13077/2/ JM\%26LS-ImaginaryConstruction-paper-DesignCinema.pdf [Erişim Tarihi 16 Ekim 2018]

Stieve, T. (2013) "Landscape of the unknown: mobilizing three understandings of landscape to interpret American and Indian cinematic outer space", GeoJournal, Sayı 78, s.165-180, doi: 10.1007/s10708-011-9436-4.

Stokrocki, M. L. ve Delahunt, M. (2008) "Empowering Elementary Students' Ecological Thinking Through Discussing the Animé Nausicaa and Constructing Super Bugs", Journal for Learning through the Arts, Sayı 4, s.1-30.

Tomos, Y. (2013) "The significance of anime as a novel animation form, referencing selected works by Hayao Miyazaki, Satoshi Kon and Mamoru Oshii", Basılmamış Doktora Tezi, Aberystwyth University, Aberystwyth, UK.

Tschida, D. A. (2004) "The Crocodile Hunter, the Jeff Corwin Experience, and the Construction of Nature: Examining the Narratives and Metaphors in Television's Environmental Communication", Basılmamış Doktora Tezi, University of Missouri, Columbia, MO, USA.

Varotto M. ve Rossetto, T. (2016) “Geographic film as public research: re-visualizing/vitalizing a terraced landscape in the Italian Alps (Piccola terra/Small land, 2012)", Social \& Cultural GeoGraphy, Sayı 17:8, s.1140-1164, http://dx.doi.org/10.10 80/14649365.2016.1155731

Weihsmann, H. (2011) “Ciné-City Strolls: Imagery, Form, Language and Meaning of the City Film", Editörler: François Penz ve Andong Lu, Urban Cinematics Understanding Urban Phenomena Through the Moving Image, Intellect, s.23-41.

Yokohari M. ve Bolthouse, J. (2011) “Keep it alive, don't freeze it: A conceptual perspective on the conservation of continuously evolving satoyama landscapes", Landscape and Ecological Engineering, Sayı 7, s.207-16.

\section{Filmografi}

Avatar (2010) Yönetmen, James Cameron.

Lawrence of Arabia (1962) Yönetmen, David Lean.

Like Father (2001) Yönetmenler, Richard Grassick, Ellin Hare, Sirkka-Liisa Konttinen, Murray Martin.

Lord of the Rings ( 2001-2003) Yönetmen, Peter Jackson.

My Neighbor Totoro (1988) Yönetmen, Hayao Miyazaki.

Piccola Terra (2012) Yönetmenler, Michele Trentini ve Marco Romano.

Places in the Heart (1984) Yönetmen, Robert Benton.

Red Desert (1964) Yönetmen, Michelangelo Antonioni.

Sheffield, City on the Move (1971) Yönetmen, Jim Coulthard.

The Spitfire Grill (1996) Yönetmen, Lee David Zlotoff.

The Story of the Weeping Camel (2003) Yönetmenler, Byambasuren Davaa, Luigi Falorni.

The Woodlanders (1998) Yönetmen, Phil Agland. 